\title{
Asketisme Yesus Sebagai Dasar Pengajaran Orang Tua Kepada Anak
}

\author{
Meriani Bintoen \\ Institut Agama Kristen Negeri Toraja \\ Merianibintoen01@gmail.com
}

\begin{abstract}
This paper examines the importance of character education and religious education for children to become good individuals in association with the community and in the family. As Christians, parents need to take the actions of Jesus as an example and role model so that the child's character can be well formed, and not easily carried away by the associations around him. This study aims to explain the importance of making Jesus an example in educating children, both in family education and education in schools and churches.

Abstrak: Tulisan ini mengkaji tentang pentingnya pendidikan karakter dan pendidikan agama bagi anak agar menjadi pribadi yang baik dalam pergaulan dengan masyarakat dan dalam keluarga. Sebagai orang Kristen, orang tua perlu mengambil tindakan Yesus sebagai teladan dan panutan agar karakter anak dapat terbentuk dengan baik, dan tidak mudah terbawa pergaulan di sekitarnya. Penelitian ini bertujuan untuk menjelaskan pentingnya menjadikan Yesus sebagai teladan dalam mendidik anak, baik dalam pendidikan keluarga maupun pendidikan di sekolah dan gereja.
\end{abstract}

\section{Pendahuluan}

Sejak dilahirkan, keluarga adalah bagian pertama yang dijumpai oleh anak. Keluarga cukup berperan besar dalam tumbuh kembang anak. Tentang bagaimana anak memperoleh pendidikan karakter, ajaran agama, bahkan cara bergaul juga diperoleh dalam keluarga. Jadi keluarga utamanya ayah dan ibu cukup berperan penting karena mereka adalah pendidik pertama bagi perkembangan karakter anak. Karakter anak terbentuk tergantung dari didikan pertama yang ia dapatkandari orang-orang terdekatnya. Itulah sebabnya penting bagi keluarga untuk mengajarkan ajaran-ajaran agama bagi anak. Salah satu ajaran pokok dan penting yang wajib ditanamkan kepada anak adalah asketisme Yesus sebagai dasar pengajaran keluarga kepada anak.

\section{Tujuan dan Manfaat}

Kajian ini bertujuan menjelaskan pentingnya peran keluarga dalam tumbuh kembang anak dan dalam pembentukan karakter anak, serta pentingnya membangun dasar yang kuat kepada anak mengenai perilaku baik, dan untuk memberikan pemahaman kepada keluarga Kristen mengenai pentingnya menanamkan pengajaran asketisme Yesus kepada anak.

Manfaat dari kajian ini adalah agar karakter anak terbentuk dengan baik dan agar kehidupan anak bertitik tolak pada asketisme Yesus.

\section{Pembahasan}

Asketisme adalah ajaran mengenai tindakan yang sejalan dengan ajaran agama, yang menekankan perilaku jujur, kasih dan berbakti. Pentingnya asketisme ini diterapkan dalam 
keluarga Kristen, adalah karena Yesus sendiri memberikan teladan yang demikian. ${ }^{1}$ Ketika keluarga mampu menerapkan asketisme Yesus ini sebagai dasar ajaran kepada anak, tentunya karakter anak akan terbentuk dengan baik. Anak akan berperilaku baik apabila keluarga mampu membangun dasar asketisme Yesus sejak awal sebelum anak memperoleh pergaulan yang lebih jauh dan terjun ke dalam lingkungan yang lebih luas. Karakter anak dipengaruhi lingkungan dimana ia tumbuh, berkembang, dan bergaul. Itulah sebabnya penting menanamkan dasar yang kuat mengenai ajaran agama sejak dini.

Dalam kehidupan dan budaya orang Toraja, Tongkonan atau tempat berkumpulnya rumpun keluarga memberikan identitas kepada anggota keluarga, dan didalam Tongkonan pula karakter anggota keluarga dibentuk. Demikian pula peran keluarga secara umum. Keluarga memberikan identitas kepada anak, bagaimana anak dinilai dan dikenal itu tergantung dari cara keluarga membentuk jati diri anak. Ajaran agama menjadi bagian penting dalam pembentukan karakter anak karena hal tersebut juga akan berpengaruh pada pandangan masyarakat terhadap anggota keluarga utamanya anak. $^{2}$

Pendidikan di dalam keluarga memang penting karena pembentukan karakter dimulai dari keluarga, tetapi pendidikan secara formal juga sangat menolong karena cakupannya cukup luas. Itulah mengapa pemerintah berusaha membangun sekolah-sekolah, dimana didalamnya semuanya sudah diatur dan dirancangkan struktur pembelajarannya. Di dalam sekolah anak diajar mengenai mata-mata pelajaran yang telah ditentukan, didikan tentang moral dan karakter anak, maupun ajaran tentang agama. Di dalam msayarakat juga pendidikan mengenai ajaran agama sangat penting sehingga gereja dibangun sebagai pusat pendidikan agama. Jadi secara umum pendidikan sangat diperlukan. ${ }^{3}$

Iman dan karakter anak tentu dipengaruhi oleh budaya di lingkungan dimana ia tumbuh. Ketika budaya dan cara hidup orang disekitarnya masih memegang ajaran-ajaran yang baik dalam berperilaku tentu anak juga akan melakukan hal yang sama. ${ }^{4}$ Tetapi ketika anak hidup dalam lingkungan yang amburadul dan hidup tidak sesuai dengan budaya dan ajaran agama yang baik, maka bisa saja anak terpengaruh untuk hidup pada pergaulan yang kurang sehat, dimana moral dan karakter anak akan menjadi kacau dan rusak. Hal ini tentunya harus menjadi pertimbangan bagi orang tua pula dalam menentukan tempat yang baik bagi anak untuk bergaul. Anak akan cenderung mengambil contoh perilaku dari lingkungan dimana ia berada, baik dalam keluarga maupun masyarakat secara umum. Jadi penting bagi orang tua untuk tetap memberikan contoh yang baik, pendidikan yang baik, dan tentunya menekankan ajaran agama Kristen.

Asketisme Yesus menjadi ajaran dan didikan yang paling tepat bagi anak, dimana orang tua dapat mengajarkan perilaku-perilaku dan teladan yang dilakukan oleh Yesus. Teladan Yesus nyata

\footnotetext{
${ }^{1}$ Rannu Sanderan, “Disiplin Asketisme Dan Harmoni Kontribusi Disiplin Diri Bagi Pengembangan Pendidikan Kristen" (2021), https://osf.io/frsnz/.

2 Jurnal Teologi, Kristen Kontekstual, and Rannu Sanderan, “Heuristika Dalam Pendidikan Karakter Manusia Toraja Tradisional" 3 (2020): 306-327.

${ }^{3}$ Rannu Sanderan, “EXEMPLARY: Menemukenali Kunci Pendidikan Kristen Bagi Anak Dalam Keluarga Dan Pembelajaran Agama Di Sekolah" (2021), https://osf.io/bntrk/.

${ }^{4}$ Ibid.
} 
dalam tindakannya, Ia setia, taat, dan tindakan-Nya dapat dirasakan oleh umat-Nya. Perilaku baik anak juga penting untuk dirasakan oleh masyarakat. ${ }^{5}$ Seseorang yang menjadi teladan bagi anak sangat penting, karena akan berpengaruh pada cara pandang anak terhadap orang itu dan akan menjadi contoh bagi anak. Anak akan berperilaku sebagaimana yang ia tangkap dari apa yang ia teladani, oleh sebab itu penting memilih tokoh yang baik untuk dijadikan teladan dalam mendidik anak. ${ }^{6}$ Yesus mengajarkan tentang kejujuran, kasih dan perbuatan-perbuatan yang baik. Ketika orang tua mampu menjadikan Yesus sebagai teladan bagi anak maka karakter anak akan terbentuk dengan baik karena anak memiliki teladan yang baik pula. Karakter yang baik dan kuat tidak akan mudah dipengaruhi oleh lingkungan yang membawa hal-hal negatif. Orang diperhadapkan dengan berbagai keputusan di dalam menghadapi lingkungan sekitarnya, dan dalam menentukan suatu keputusan tentunya diperhadapkan dengan berbagai pertimbangan yang mungkin tepat untuk dirinya. ${ }^{7}$ Disaat anak sudah memiliki ajaran agama yang kuat dan karakter yang baik, ia tidak akan mudah dipengaruhi oleh pergaulan-pergaulan yang dapat membawanya kepada hal yang buruk. Orang tua harus memahami kebutuhan yang dibutuhkan anaknya, bukan hanya kebutuhan secara fisik saja tetapi kebutuhan dalam hal pendidikan juga. Orang tua harus memahami lingkungan seperti apa tempat anaknya bergaul dan berkembang sehingga mampu memberikan didikan dan ajaran yang tepat.

Alkitab menjadi pusat pendidikan bagi keluarga Kristen. Penting bagi orang tua Kristen untuk mengajarkan apa yang difirmankan Tuhan kepada anak. Kita hidup di zaman dimana semuanya modern, budaya juga berkembang dan bahkan ada yang sudah tidak sesuai dengan ajaran-ajaran dan norma-norma yang sebenarnya, pergaulan dari berbagai macam gaya hidup bersatu dalam suatu lingkungan sehingga dapat membawa hal yang negatif. Hal-hal inilah yang menjadi tuntutan bagi gereja dan orang tua Kristen untuk tetap menanamkan budaya yang baik dan ajaran-ajaran agama yang kuat terhadap anak. ${ }^{8}$ Alkitab mengajarkan tentang pengendalian diri dalam menghadapi lingkungan yang kurang sehat. Ini penting ditanamkan kepada anak agar anak tidak terbawa dalam pergaulan yang buruk tetapi anak tetap dapat berlaku baik dalam kesehariannya karena dapat mengendalikan dirinya dari nafsu dan pergaulan yang tidak baik. Asketisme Yesus dapat dilihat dalam Galatia 5:22-23 melalui buah-buah Roh, yang di dalamnya menekankan kasih, sukacita, damai sejahtera, kesabaran, kemurahan, kebaikan, kesetiaan, kelemahlembutan, dan penguasaan diri.

\section{Kesimpulan dan Saran}

Secara umum, karakter memang perlu dibentuk dengan baik. Karakter yang baik tentu akan mendapat perhatian positif dari lingkungan dimana kita berada. Pendidikan karakter begitu ditekankan di keluarga, sekolah-sekolah maupun di gereja. Hal ini menandakan bahwa karakter

\footnotetext{
${ }^{5}$ Rannu Sanderan and Yohanes Krismantyo Susanta, "Pemahaman Tentang Sayap Dalam Kitab Rut," KAMASEAN: Jurnal Teologi Kristen 2, no. 1 (2021): 47-58.

${ }^{6}$ Rannu Sanderan, "EXEMPLARY: Menemukenali Kunci Pendidikan Kristen Bagi Anak Dalam Keluarga Dan Pembelajaran Agama Di Sekolah."

7 Rannu Sanderan, "INTUISI: Pendalaman Gagasan Hans-George Gadamer Tentang Intuisi Sebagai Supralogika," Jurnal IImiah Religiosity Entity Humanity (JIREH) 2, no. 2 (2020): 114-125.

8 Rannu Sanderan, “EXEMPLARY: Menemukenali Kunci Pendidikan Kristen Bagi Anak Dalam Keluarga Dan Pembelajaran Agama Di Sekolah."
} 
yang baik memang penting. Orang tua, masyarakat dan gereja cukup berperan baik menjadi pendidik bagi anak maupun menjadi teladan bagi anak karena anak akan cenderung berperilaku sebagaimana yang ia lihat dilingkungan sekitarnya. Menjadikan asketisme Yesus sebagai pusat pendidikan karakter bagi anak adalah pilihan yang paling tepat, dimana Yesus memberikan contoh yang nyata dalam setiap tindakannya. Yesus menjadi teladan dalam perbuatan-perbuiatan baik, dalam hal kejujuran, kasih, adil, taat dan sebagainya yang tentu juga sangat tepat untuk dijadikan pijakan dalam membentuk karakter yang baik.

Penulisan kajian ini adalah untuk menjelaskan pentingnya pembentukan karakter anak yang dibentuk berdasarkan teladan yang tepat. Oleh karena itu, tulisan ini diharapkan dapat menjadi

acuan dalam mendidik anak dengan baik agar dapat mencerminkan perilaku yang baik di tengah keluarga, masyarakat, dan gereja dimana ia tinggal.

\section{Refrensi}

Rannu Sanderan. “Disiplin Asketisme Dan Harmoni Kontribusi Disiplin Diri Bagi Pengembangan Pendidikan Kristen" (2021). https://osf.io/frsnz/.

_ . "EXEMPLARY: Menemukenali Kunci Pendidikan Kristen Bagi Anak Dalam Keluarga Dan Pembelajaran Agama Di Sekolah" (2021). https://osf.io/bntrk/.

Sanderan, Rannu. "INTUISI: Pendalaman Gagasan Hans-George Gadamer Tentang Intuisi Sebagai Supralogika.” Jurnal Ilmiah Religiosity Entity Humanity (JIREH) 2, no. 2 (2020): $114-125$.

Sanderan, Rannu, and Yohanes Krismantyo Susanta. "Pemahaman Tentang Sayap Dalam Kitab Rut.” KAMASEAN: Jurnal Teologi Kristen 2, no. 1 (2021): 47-58.

Teologi, Jurnal, Kristen Kontekstual, and Rannu Sanderan. "Heuristika Dalam Pendidikan Karakter Manusia Toraja Tradisional” 3 (2020): 306-327. 